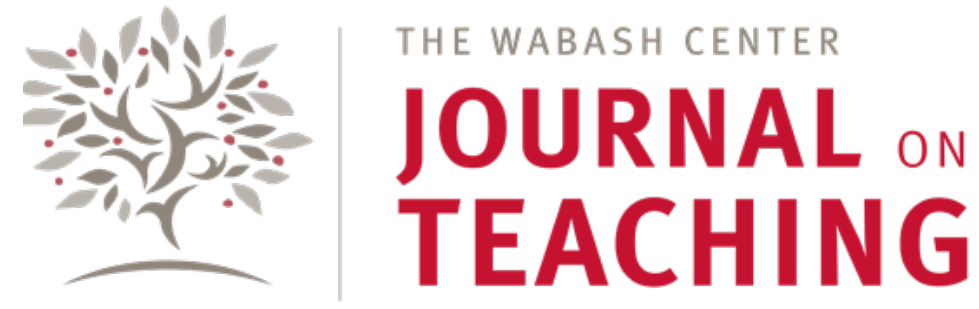

ARTICLE

\title{
Teaching Metaliteracy in the Religious Studies Classroom
}

\author{
Marianne Delaporte Kabir \\ Sacred Beginnings Workshops \\ Sanjyot Pia Walawalkar \\ Skyline College
}

\begin{abstract}
This paper reflects upon the collaborative work between a professor and a librarian who constructed a course on religious communes in the United States implementing the seven elements of metaliteracy as put forth by Jacobson and Mackey (2013). The shifting terrain of information literacy is hard enough for librarians to traverse, but it can feel insurmountable for professors in the classroom. Working side by side with a librarian can be one of the most fruitful ways for professors to advance in this field. The seed for this project was a collective intent to create lifelong learners with strong habits of inquiry rather than merely teaching students discrete search strategies and skills. By using technology and team-based learning, the collaborators hoped to open up the students to a critical yet empathetic understanding of religion and to help them develop as informed users and creators on the internet.
\end{abstract}

\section{KEYWORDS}

metaliteracy, metacognition, embedded librarian, instructional technologies, cults, new religious movements, Synanon

This paper reflects upon the collaboration of a tenured professor of religious studies and a recent tenure-track humanities librarian (the teachers) in developing a course entitled "Religious Communes in the United States." At the time, both taught at Notre Dame de Namur University (NDNU). NDNU is a small Catholic liberal arts university that serves approximately 1700 students with class sizes ranging from nine to thirty students per class, averaging a faculty-student ratio of one to twelve. Religious studies are general education (GE) courses at NDNU; the courses must therefore serve a variety of interests and are assessed by their ability to foster critical thinking, teach written communication, information literacy, and oral communications, as well as engage students in the school's mission.

\section{The Professor}

Despite being a Catholic university with required religious studies courses, the professor observed that when students study religion there is often a strong gut reaction-of discomfort, protective love, or even, hatred. Students can be dismissive of religions or spiritualities outside of the mainstream and so fail to analyze and understand their complexities or even, often, 
to understand them to be religions. By moving the subject of religion away from traditional world religions to new religious movements (NRMs), she hoped to enable students to think about religion overall and its effects on society and individuals more easily. What is religion and how does it interplay with society? How does it critique or accept social norms? In the spirit of analyzing and understanding religious motivations and faiths she also did not want students falling into the easy trap of viewing new religious movements as "cults." She hoped that analyzing one religious commune in depth would allow students to see how all religions might have a combination of the utopian and the dystopian. Little work has been done on teaching NRMs but that which has points to similar issues with the subject and similar solutions (see Zeller [2015] and Gallagher [2007] on overcoming resistance to studying NRMs). Engaging students in active learning disrupts their preconceptions and biases as they become the ones who teach themselves and each other. This can then be expanded to any religious studies course so that students come away with a more engaged and open attitude to religions other than their own. As religious studies scholar Zeller notes:

[T]raditional pedagogies predicated on the professor as fount of knowledge transferring said knowledge to receptive students simply does not work very well when teaching NRMs. Students possess too much resistance, and the cultural pressure against taking new religious movements seriously is too strong. Rather, instructors must utilize techniques that are student-centered and engage students in active learning, since only the students themselves can teach themselves to overcome their presuppositions and assumptions. $(2015,123)$

The professor noticed that her students tend to view religion and research similarly-as things perhaps imposed upon their lives that they experience in a passive manner. One of her goals for this course was to teach students that both religion and research are alive, changing constantly, and that students themselves can be part of this conversation, not as passive receptors, but as engaged actors.

\section{The Librarian}

Meanwhile, on the other side of campus the librarian was becoming increasingly frustrated with the one-shot information literacy instruction model (a single session conducted by a librarian on invitation by the course instructor to teach their students to locate, evaluate, and use needed information effectively). She reached out to the professor to discuss the inadequacies of this model. Despite being an ardent supporter of the library, the professor concurred that she too found the one-shot instruction sessions ineffective. What she always loved about research was the joy of the chase, the mazes and false turns, the eureka moment-and she wanted to share that joy with her students. In her view, one-shot library visits were helpful in moving students forward with an assignment, but did not help move them towards this feeling of joy. Moreover, she noticed that while students included the proper resources in their references after a one-shot library instruction, they rarely actually integrated these sources fully into their papers; they culled quotes to stuff their work without truly being in conversation with the references. The traditional one-shot model offers limited opportunities to make a real impact on students. It does not build in them a solid foundation of information literacy or dispositions that help them succeed academically and also lead to lifelong independent learning skills.

The professor and librarian thus shared many of the same teaching goals. Both wanted students to understand that learning does not entail accumulation of information, and research is not simply searching for, locating, collecting, and summarizing information. Rather, education involves learning, unlearning, and relearning of concepts, or what Zeller calls, "unsettling and resettling" $(2015,129)$. Furthermore, both learning and research are active and interactive; are solitary, and at the same time, collaborative processes. In addition they wanted students to understand the value of information in multiple formats and with varying levels of access, to develop the flexibility to move from one format to another, and to be able to make connections, draw comparisons, and determine gaps in information found. Lastly, they felt that students could learn new technologies and create and share digital resources in a safe, collaborative environment.

To provide students with such transformative learning experiences, they decided to implement Thomas Mackey and Trudi Jacobson's metaliteracy model (2014) in their teaching practice and course design. They knew that the task at hand was too enormous to be accomplished through traditional lecture-based course sessions interspersed with a few lecture-based library sessions. They committed to designing and teaching the course collaboratively, guided in part by the metaliteracy model, creating and sustaining an inclusive learning community where there was ongoing, sustained communication and support between the course instructor, the embedded librarian, and students. Students were taught metaliteracy theory as the course progressed and journaled regularly about how they were researching and learning. 


\section{What is Metaliteracy?}

Since the term "information literacy" was first coined in the 1970s, it has undergone several revisions to stay in step with the constantly changing information landscape. In a 1974 report written on behalf of the National Commission on Libraries and Information Science, Paul Zurkowski defined information literates to be those who "have learned techniques and skills for utilizing the wide range of information tools as well as primary sources in molding information solutions to their problems" $(1974,6)$. When Zurkowski's report came out, information was mainly text-based and primarily available in carefully curated collections. An information literate individual would be able to determine the nature and scope of the information needed; locate information sources from a curated collection, independently or with help of a librarian; and evaluate its relevance to their topic or interest. Therefore, teaching students to use library resources and tools, and retrieve librarian-mediated information, was enough to help them become information literate.

On the other hand, the information landscape of the twenty-first century is instant, dynamic, uncertain, burgeoning, open, participatory, and democratized. It is marked by blurred boundaries between creators and audiences, an absence of curation, and a preference for sharing over privacy. In such an environment, simply teaching students how to determine their information needs and how to locate, utilize, and cite their resources is not enough. It requires teaching students to become active, empowered learners who can navigate and participate in this complex information landscape. The Association of College and Research Libraries (ACRL) Framework adopted in 2016 provides an expanded definition of information literacy as a "set of integrated abilities encompassing the reflective discovery of information, the understanding of how information is produced and valued, and the use of information in creating new knowledge and participating ethically in communities of learning" (ACRL 2016). The revised definition and the ACRL Framework draw heavily upon the concepts of metaliteracy, as set forth by Jacobson and Mackey (2013), that views students as consumers and creators of information in collaborative spaces and demands behavioral, affective, cognitive, and metacognitive engagement with the information ecosystem (ACRL 2016, 2). The seven elements of the model include the ability to:

1. Understand format type and delivery mode

2. Evaluate user feedback as an active researcher

3. Create a context for user-generated information

4. Evaluate dynamic content critically

5. Produce original content in multiple media formats

6. Understand personal privacy, information ethics, and intellectual property issues

7. Share information in participatory environments (Jacobson and Mackey 2013, 87)

While these elements are aimed at library sciences, the first four are equally critical in teaching religious studies and this paper will define each element in discussion about this particular class on communes.

\section{Course Topic, Structure, and Learning Communities}

The course, "Religious Communes in the United States," began with an overview and discussion of NRMs, their portrayal in the media, and possible biases against NRMs. A historical overview of religious communes in the United States followed, enabling students to explore common themes (family, property, work, women) in depth. The class spent time throughout the semester analyzing negative portrayals of NRMs in the mainstream media, creating a counter-environment to the general cultural environment that misrepresents and demonizes these movements (Wiersma 2016, 95-99). This was accomplished by listening to podcasts on cults, discussing the narrative of cults found in popular culture (from Arthur Conan Doyle's A Study in Scarlet [(1887) 2011] to Unbreakable Kimmy Schmidt [Fey et al. 2018]) and noting similar prejudices in the students' own study of the religious commune of Synanon.

For the last seven weeks of the semester, students were grouped into teams for an in-depth research project on one aspect of 
Synanon (history; belief system; major figures and places; and women/minorities/children). ${ }^{1}$ The professor chose Synanon in part because it is a topic on which very limited scholarly content exists, particularly from a religious studies context. Synanon began as a drug rehab in Santa Monica, California in 1958 but expanded to become a religious commune in 1974, moving to Northern California, near to NDNU. The commune fell apart in the 1980 s due to tax evasions and bad behavior on the part of the leadership. Despite there being little academic work on Synanon as a NRM it does have a strong presence on the internet and in popular culture. ${ }^{2}$

The librarian designed three library sessions to include discussions in groups, group learning activities, and hands-on searching of online archives curated by ex-members, news reports, and legal documents. Each librarian-led session was followed by research-only sessions in the library where students worked on their research assignments in teams with the feedback, direction, and support of their professor and the embedded librarian. The discussion-based library sessions and research-only sessions were planned to avoid passive acquisition of lecture material and encourage students to engage with their learning process more actively. As Reale in her book Becoming an Embedded Librarian points out:

Learning begins to shape in a learning community when students grapple with new ideas and concepts, navigate through the messy, confusing process of understanding the concepts, and clarity slowly evolves as their ideas are critically and respectfully questioned, and they are encouraged to fine-tune or refine their ideas and perspectives based on conversations and diverse viewpoints in the learning community. $(2016,87)$

These designated research days prepared students to purposefully collaborate with their team members, draw on each other's strengths, learn from and with each other, and divide and carry out responsibilities to ensure successful completion of team outcomes.

The second half of this paper examines how the seven elements of metaliteracy were implemented in this course. There is overlap between assignments and elements as the teachers found that some elements were more difficult-and more important-for students to grasp than others. This is true of the first element: understanding format type and delivery mode.

\section{The Seven Elements of Metaliteracy}

\section{Understand Format Type and Delivery Mode}

This first metaliteracy element was implemented in all aspects of the course-lectures, readings and assignments, and embedded library sessions. The course materials included a combination of books, peer-reviewed and newspaper articles, websites, blogs, films, online videos, oral history narratives, as well as fictional work (an early Sherlock Holmes story dealing with Mormons [Doyle (1887) 2011]). Parting from the traditional research paper, students were required to share their research and actively comment on each other's research through peer teaching and the use of online collaboration tools such wikis, blogs, videos, and podcasts. Led by the librarian, the class discussed how each of the online formats are different and suitable for different kinds of content but also how the information presented in various formats supported and complemented each other and allowed them to present their research more comprehensively.

The librarian introduced students to the idea that research is not merely seeking discreet answers to problems but is characterized by experts offering and negotiating varied competing perspectives as part of an ongoing conversation, and that an unequivocal answer or solution might or might not be established through this process (ACRL 2016, 8). With technological advances in scholarly communication, experts might choose to communicate their research perspectives formally (books, peer-reviewed articles, interviews with other experts) or informally (social media) where novice learners and experts at all levels can join the conversation. Students were made aware, as Jacobson and Mackey state, that "the value of information

\footnotetext{
1 These teams were organized and assessed using methods outlined by Michaelsen and Sweet (2008). Students were put into teams based on a series of questions involving their availability and affinities. They filled out assessments of themselves and their team members twice during the semester. While students had generally negative opinions of team-based work at the start, this system of accountability helped ease the process and the majority of students reported a positive experience at the end of the semester.

2 Synanon (Quine [1965] 2010) stars Eartha Kitt and Edmund O’Brien. It is a largely positive portrayal of early Synanon. Another film, Attack on Fear (Damski [1984] 2004), gives a grimmer portrayal of the later part of Synanon, focusing on the journalists from the Point Reyes Light who won a Pulitzer for their investigative writing. Rod Janzen's 2001 monograph on the subject is one of the few academic works on the topic.
} 
does not correspond to its packaging, or wrapper" (2013, 87). As Jacobson and Mackey rightly point out, students are often taught to determine the authority and reliability of information based solely on its type or modality: "In academic settings, blogs and wikis may not be seen as academic, and thus, discounted as reliable sources in either its format or the way it's received" (2013, 87). This issue was reiterated during an in-class learning activity in which students looked at primary and secondary source materials, academic and non-academic blogs, and scholarly books and articles. The professor and librarian made sure that some of the selected blogs, articles, and books were written by the same author, using for example, Philosophy: A Short, Visual Introduction (2015) by Scott Paeth of DePaul University and his blog, Against the Stream (2019). The librarian clarified that the length of time it takes to get an article published changes the conversation; the results are supposed to have a universal quality which transcends time. Blogs, on the other hand, are a quick and personal way for experts to share information and get feedback from colleagues, often in preparation for further published work, or, in other cases, on a subject which is ephemeral. While the professor and the librarian were able to convince students of the value of information in non-traditional delivery modes for scholarly communication, students struggled with establishing the expertise and credibility of authors publishing in open and social network environments. Students did learn to appreciate the fluidity and movement in academic research, however; one student wrote in her journal, "By looking at articles and seeing whom they cite in their work I was able to go back and see what the original article was about... I was able to see how each article built on the next and offered something unique about the conversation."

Students often have difficulty distinguishing primary from secondary sources, particularly when their formats are identical. Studstill and Cabrera (2010) note that many of the definitions professors use to describe primary sources are confusing to students and inadequate in preparing them to do research with any sophistication. Being aware that the same source can shift from being a primary to a secondary source, depending on the questions one is asking, is an important step in a student's development. Studstill and Cabrera point to the importance of context sensitivity in evaluating a source as primary or secondary and argue that religious studies questions fall within two categories: descriptive and non-descriptive (2010, 89). When asking a descriptive question ("How was 'The Game' played at Synanon?”) then “any direct representation of the topic is a primary source” (Studstill and Cabrera 2010, 90). (In this case, the Synanon museum website's audio files). However, the issue is more complex when the question is non-descriptive ("How did 'The Game' played at Synanon affect American society?”) In this case, the authors point out, research will be most effective if students use scholarly secondary sources as well as multiple primary sources. Students had issues identifying primary sources and secondary sources. The librarian and professor began addressing this problem by doing several exercises found in the Studstill and Cabrera article (2010). Still, the problem persisted. While students could easily identify the primary sources when asking descriptive questions, they often misidentified sources or used them as secondary sources while identifying them as primary sources.

In addition to the variety of information available online and in the library, the professor had chosen Synanon because of its relative modernity and geographical proximity to the university. This allowed the introduction of a dynamic format type: people who had encounters with Synanon. Don Stannard-Friel, a sociologist who had experienced the Synanon Game as a young sociologist, ${ }^{3}$ and a woman who had been a child in Synanon and who had worked with Stannard-Friel, were invited to come and speak to the class. One student interviewed a past member of Synanon on their own and another visited the original Synanon building in Santa Monica. These meetings allowed the students to realize that their research was about real people with complex lives; that "cults" or religious communes should not be dismissed easily, as the popular press does. Interactions with these people also contradicted some information students had found in other sources and added new information, complicating the picture. The students were particularly intrigued by the fact that they had information which the person who lived on the commune for years as a child did not have. By using these "experts" as sources, the students themselves contributed new information to the study of Synanon.

\section{Evaluate User Feedback as an Active Researcher}

The librarian discussed how Web 2.0 technologies and applications have made it possible for users at all levels-from mere observers to experts-to enter scholarly conversations and generate content. ${ }^{4}$ This phenomenon has taken away the authority formerly granted to a select few experts to shape the research conversation and has democratized information; users now have access to a vast body of information and a wide range of perspectives. Such an environment requires students to continuously apply a fact-checking and critical thinking filter to sift through what is usable and unusable and determine what needs further research. Using examples of user comments on blogs, websites, and YouTube videos that students read as part of their coursework, the librarian and professor demonstrated how to differentiate between research-worthy comments that contain critical information and comments that are irrelevant or opinion-based. Relating to this exercise, they urged students to evaluate all information, whether it is the information

\footnotetext{
3 Stannard-Friel is the author of Harassment Therapy: A Case Study of Psychiatric Violence (1981) which covers therapies influenced by the Game.

4 There is scholarly dispute over whether or not the Web 2.0 has actually democratized access to information, which cannot be covered here (Inefuku 2017 ; see also Ess 2018).
} 
source such as a book, article, website, a blog, or video or information about that source such as unfiltered and unedited reviews, rating, comments, and feedback. As part of their assignment, students were required to comment on each other's wikis and blogs. Students were able to recognize the varying quality and relevance of their classmates' comments and correlate this to their own differing levels of engagement with class, assignments, and their own ownership of their class performance. This hands-on exercise was a preparatory step in making them aware of the "need to differentiate between experts in the field and observers and participants, without discounting the views of these effectively contributing through social media” (Jacobson and Mackey 2013, 88).

Mackey and Jacobson (2014) point to the opportunities and obstacles posed by Web 2.0 and the omnipresence of Google. On the one hand, the ability to find previews and book summaries or even digitized versions of books on Google, as well as ratings and comments on social media sites, might lead the learner to expand the possibility of locating resources. On the other hand, finding this range of information might lull the information seeker into believing that they have found everything that can be found to satisfy their information need and they may abandon their search prematurely (Mackey and Jacobson 2014, 71-72). The professor and librarian continually urged students to understand that they are bound to experience information overload and that to make the most of the information they have available at their fingertips, they need to be focused and active in their research process.

\section{Create a Context for User-Generated Information}

The teachers addressed the information generated by people related to Synanon in some way while working with this element of metaliteracy. As previously stated, the team assignment required students to research one aspect of Synanon in depth. There is a considerable amount of information on the web about Synanon, particularly primary sources, and the movement is recent enough for students to be able to track down people who had experience with Synanon, had written on the subject, and were willing to be interviewed. In such research circumstances, where familiar markers like books and peer-reviewed articles are missing, it is all the more important that learners have developed strong habits of critical thinking-with which they can recognize the relevance of the information they find, situate the information in the process, and understand and determine the context, time, and location on their own. In the absence of comprehensive resources, information is available in discrete units-websites, personal narratives, videos of re-enactment of Synanon activities, FBI reports, news articles, audio clips of interviews-produced by journalists, key players, participants, members, observers, and passersby. To be able to recognize the voice and the purpose of the information one needs to understand the context in which the information has been produced. While the teachers both discussed the importance of contextualizing content, this was something that the students found most difficult to grasp and put in practice. As NRM scholar Cowan (2007) notes, print resources are scarce for NRMs and students must therefore learn to navigate the web critically.

A primary text which all of the students turned to was Paul Morantz's website (2019), which was a particular issue. Morantz is the lawyer who was bitten by a rattlesnake Synanon members placed in his mailbox in 1978. He maintains an extensive website on the history of Synanon, including many primary text documents. However, his interpretation of the events is, as one might imagine, biased, as he was a major player in the story of Synanon's demise. Students tend to shy away from this sort of material rather than grappling with how to use it, yet this is exactly the sort of material they will continue to encounter and have to contextualize throughout their lives, whether they go on to graduate school or not.

\section{Evaluate Dynamic Content Critically}

In addition to being exposed to a vast array of information where it is difficult to establish the credibility of contributing authors and separate the expert from the novice, learners are faced with information that is dynamic and fluid. Some researchers share results and perspectives even when their work and research is ongoing and continue to update their social networking sites until their research project is completed and they have published their work formally. On the other hand, novice experts and individuals, who are able and eager to create content online, are constantly adding, editing, and deleting content from this vast body of information. The librarian stressed the importance of being alert to these changes, and of being flexible as the content or the delivery mode of the content changes and requires users to adapt. As Cowan notes, the fluidity of the internet is one of the great pedagogical advantages in studying NRMs, allowing students to see their movement in almost real time $(2007,299)$. This lesson can then be extended to more established religions, which may seem monolithic and timeless to students at first glance.

With limited well-researched information available on Synanon in traditional scholarly formats, students were encouraged to locate information online. One of the early class activities was a crowd-sourcing exercise where students posted sources they had selected to the virtual post-it board, Padlet (2020), and then discussed them in class. The discussion was effective in revealing biases and emotions, serving to jump-start the critical thinking process (Wiersma 2016, 96). Not surprisingly, students were drawn to Wikipedia. 
Rather than banning the site, the professor showed students the "inner workings" of Wikipedia (its revision history) and had students develop their own, private, wikis. ${ }^{5}$

While the librarian-led sessions and demonstrations were useful in helping students understand the importance of critically assessing all content they come across online, what was most impactful was their hands-on experience in creating and maintaining wikis, blogs, and the class website together in groups. Students were expected to present the descriptive elements of their research by means of a wiki page and present their analysis of this information in blog entries. Students witnessed content on their own wiki pages develop over time, added to and edited by different members, synchronously or asynchronously. They saw how their own understanding and analysis of the topic evolved over time as they wrote the different blog entries.

\section{Produce Original Content in Multiple Media Formats}

Creating and distributing information in multiple formats in participatory environments is an important element of Mackey and Jacobson's (2014) metaliteracy model and the teachers were successful in implementing this for the most part. As noted previously, most course assignments required students to create original content in various formats, both in teams and independently. Students wrote online reflections on readings and shared class discussions with the professor on the university's learning management system. Collaborating in teams, students created private wiki pages where they provided summaries of basic background and descriptive research relating to their specific topic. Their analysis and interpretation of the topic was presented in four blog posts over the sevenweek assignment period. Students were encouraged to write engaging and thought-provoking posts and indicate their openness to conversation that would motivate others to respond. All students were required to participate and engage with each other in the open blogosphere and comment on each other's posts. They were also required to comment on wikis that were maintained by teams other than their own. Finally, they created a podcast or a video. To the teachers' surprise, students were not eager to create audio or video content and, except for one group, opted out of this requirement. Instead they chose to perform in class. One member from each of the four groups teamed up to work on a class website on Synanon using the website builder tool Wix (2020). Each of the wiki pages and blogs created and maintained by the four teams, and a podcast created by one group, were then organized and could be accessed from a single website, making it a comprehensive site which all the students could access and use to inform their own work. Even though the students shied away from using audio and video content creation technologies, they understood how the nature of content determines the format most suited for it. What surprised the teachers was students' reluctance to learn, engage with, and create original content with content creation technologies. Initially, students found all assignments that required them to create in social media formats challenging. Working together in learning communities with sustained help from other students, the professor, and the librarian, students came to appreciate and take pride in their work on the wiki pages, blogs, and Wix page. One student wrote of the experience: "After the project was completed I saw that I worked with a lot of different kinds of media and technology. I learned how to add on to a Wix site, blog, create a wiki page, and journal about research. I feel a little more comfortable working with all those different types of things."

\section{Understand Personal Privacy, Information Ethics, and Intellectual Property Issues}

During the library sessions and research days, the librarian repeatedly emphasized that just as it is important to work collaboratively, and to gather information from a variety of sources and in multiple formats, it is also important to respect the privacy and intellectual property rights of those sources, irrespective of whether the content creators are people or institutions, or whether the information is available for free or is behind a paywall. Along with establishing the identity and credibility of a content creator, the librarian demonstrated how to understand usage rights, locate what license the content was published under, and ensure that all attribution requirements were met when content was used or repurposed for student research projects. She also trained students in locating materials labeled for noncommercial usage, and in providing correct attributions for creative commons licensed content. Evaluation of the wikis, blogs, and class website indicated that students for the most part provided citations when necessary and used images and other media that were labeled for noncommercial reuse. In the final weeks of the class as the teachers sought the Institutional Review Board's approval for possible publication of their work, students had a first-hand look at respecting personal privacy as part of engaging in a participatory, online community. The students understood how the teachers would use their work and gave written consent for student-generated data to be incorporated in research. Students knew from the outset that this was a new course and that the teachers were experimenting with teaching metaliteracy in the religious studies classroom. When the teachers explained how the class had inspired them to work collaboratively on a paper, students were generally enthusiastic about this possibility. This further strengthened the teachers' claim that knowledge is built in collaboration.

\footnotetext{
5 In a second iteration of the course, the professor worked with Wiki Education (2020) to create assignments that led students through the process of evaluating, editing, and posting Wikipedia articles. It was an invaluable-though time intensive-experience.
} 


\section{Free-Flowing Contributions: Sharing Information in Participatory Environments}

As noted, students were expected to create and publish information in teams, using online collaboration tools, keeping a global audience in mind. The sharing of this information took place in stages. Initially, the wikis and blogs were open only to the specific teams as content was being created and refined collaboratively within the group. After a few weeks, the wikis and blogs were shared with the entire class, to encourage engagement and feedback from all. The teams then used this feedback to further refine their work. The benefit of sharing team projects was manifold: students were able to view the wikis and blogs created by other teams before the final assignment was due, which inspired them to modify and refine their own work; they were able to see how their specific projects were parts of a larger project and which gaps needed to be filled so the separate parts fit together to create a whole. Moreover, as metaliterate learners they had to "strive for independent democratic participation, while being open to free flowing contribution from others" (Jacobson and Mackey 2013, 90). In contrast to individual research papers, written in isolation and only seen by a professor, these larger team projects gave the students a greater sense of responsibility for the quality of content, compliance with copyright and privacy laws, and usage rights. They shared information which they found but could not use in their own work with others who could use it, rather than stuffing it into their work, as is often the case in the traditional research paper. Viewing other teams' work led to a healthy spirit of competition as they saw others' strengths and learned from them, altering their work along the way.

In addition to expanded competencies of collaborative creation, repurposing, and sharing of digital materials, "central to the metaliteracy model is a metacognitive component that encourages learners to continuously reflect on their own thinking and literacy development in these fluid and networked spaces" (Jacobson and Mackey 2013, 84). To engage students in such metacognitive practices, the teachers required them to maintain a research journal throughout the semester. Students were encouraged to critically assess their search process-to refine it to find better sources, and to dig deeper. They learned to adapt to new technologies and to the cognitive changes happening within themselves.

\section{Conclusion}

One noticeable common thread in the student journal narratives is a journey from feeling confused and overwhelmed to feeling a sense of ease and comfort with the research process. Students also displayed an improved sense of skill, confidence, and clarity pertaining to their research. For example one student wrote:

When the project was completed, I felt that I've grown significantly. All of the sharing of information made it easier to understand Synanon. There were many new search methods I got to use such as rearranging keywords, taking words already used from certain articles, and going on news websites and using those same search terms in there.

Another impressive student statement about difficulties with sources that looked similar and repetitive was that "just reading carefully for maybe slight differences in accounts or new insights solves these problems. Patience and careful reading is how to get around this."

Students demonstrated a shift in their understanding of religions as well. One student noted, "Learning about each respective commune was interesting because although there were similarities, every commune was different in its own way. As strange as it might sound I found myself outside of class considering what beliefs could be turned into a baseline for a commune."

The journal entries proved helpful not only to the students but also to the professor and librarian as they prepared for a second iteration of the class, reflecting upon their first experience. This led to some changes, including working with Wiki Education (2020) on public wikis and cutting back on the videos and podcasts which had proven to be one assignment too many. In addition, the elements of metaliteracy were discussed more consistently and students were asked to reflect upon them in their journals throughout the semester.

This collaborative teaching experience was of great benefit to the professor as she prepared other religious studies classes as well. Having learned to think about metaliteracy concretely rather than thinking about information literacy as a vague need as she designed her classes, she also felt more freedom in assignment preparation. She recognized that students' potential to think critically and empathetically was opened up when they were given assignments which fell outside of the classic research paper and which forced them to engage more intimately with the material at hand. Watching a student giddy from having interviewed a past commune member, seeing students' pride in their fully designed webpage, hearing them engaging critically with podcasts, it was evident that 
students had learned in a holistic manner which they could transfer to other courses. They had also developed an empathetic view of NRMs.

While this exercise in metaliteracy was aimed in particular at challenging students to looking at NRMs from a new, less biased angle, these methods and the explicit use of metaliteracy skills in the religious studies classroom can help us engage students in any religious studies subject which challenges students as they come to understand the fluid nature not only of research but also of religion. Working in teams and concentrating on research as a skill in and of itself, outside of writing assignments, helps students develop a deeper understanding of particular religious issues and enjoy the ambiguity of certain aspects of spirituality rather than fearing not getting the correct answer.

\section{BIBLIOGRAPHY}

ACRL (Association of College and Research Libraries). 2016. Framework for Information Literacy for Higher Education. http://www.ala.org/acrl/standards/ilframework.

Cowan, Douglas E. 2007. “Teaching New Religious Movements on the World Wide Web.” In Teaching New Religious Movements, edited by David G. Bromley, 291-5. Oxford, UK: Oxford University Press.

Damski, Mel. (1984) 2004. Attack on Fear. Video. Dallas, TX: Reel Media International.

Doyle, Arthur Conan. (1887) 2011. A Study in Scarlet. Leicester, UK: Thorpe.

Ess, Charles. 2018. “Democracy and the Internet: A Retrospective.” Javnost - The Public 25 (1-2): 93-101. https://doi.org/10.1080/13183222.2017.1418820.

Fey, Tina, Robert Carlock, Ellie Kemper, Tituss Burgess, and Jane Krakowski. 2018. Unbreakable Kimmy Schmidt. DVD. Universal City, CA: Universal Studios Home Entertainment.

Gallagher, Eugene V. 2007. "Responding to Resistance in Teaching about New Religious Movements.” In Teaching New Religious Movements, edited by David G. Bromley, 273-290. Oxford, UK: Oxford University Press.

Inefuku, Harrison W. 2017. “Globalization, Open Access, and the Democratization of Knowledge.” EduCause Review 52 (4): 62-63. https://er.educause.edu/articles/2017/7/globalization-open-access-and-the-democratization-ofknowledge.

Jacobson, Trudi E., and Thomas P. Mackey. 2013. “Proposing a Metaliteracy Model to Redefine Information Literacy.” Communications in Information Literacy 7 (2): 84-91. http://www.comminfolit.org/index. php?journal=cil\&page=article\&op=view\&path $\% 5$ B $\% 5 \mathrm{D}=\mathrm{v} 7 \mathrm{i} 2 \mathrm{p} 84$.

Janzen, Rod A. 2001. The Rise and Fall of Synanon: A California Utopia. Baltimore, MD: Johns Hopkins University Press.

Mackey, Thomas P., and Trudi E. Jacobson. 2014. Metaliteracy: Reinventing Information Literacy to Empower Learners. London, UK: Facet.

Michaelsen, Larry K., and Michael Sweet. 2008. “The Essential Elements of Team-Based Learning." New Directions for Teaching and Learning 116 (winter): 7-27. https://doi.org/10.1002/tl.330.

Morantz, Paul. 2019. Paul Morantz (website). http://www.paulmorantz.com.

Padlet. 2020. Padlet. https://padlet.com/.

Paeth, Scott. 2015. Philosophy: A Short, Visual Introduction. Illustrated by Joseph Novak. Minneapolis, MN: Fortress. 
Paeth, Scott. 2019. Against the Stream (blog). https://www.scottpaeth.com/.

Quine, Richard. (1965) 2010. Synanon. DVD. Culver City, CA: Sony Pictures Home Entertainment.

Reale, Michelle. 2016. Becoming an Embedded Librarian: Making Connections in the Classroom. Chicago, IL: American Library Association.

Stannard-Friel, Don. 1981. Harassment Therapy: A Case Study of Psychiatric Violence. Boston, MA: G.K. Hall.

Studstill, Randall, and Peggy Cabrera. 2010. “Online Primary Sources in Religious Studies: Active Learning Exercises for Information Literacy Instruction." Journal of Religious and Theological Information 9 (3-4): 84-112. https://doi.org/10.1080/10477845.2010.527252.

Wiersma, Hans. 2016. “Engaging Media and Messages in the Religion Classroom.” In Teaching Civic Engagement, edited by Forrest Clingerman and Reid B. Locklin, 88-108. New York, NY: Oxford University Press.

Wiki Education. 2020. WikiEdu. https://wikiedu.org/.

Wix. 2020. Wix. https://www.wix.com.

Zeller, Benjamin E. 2015. “'But Aren’t Cults Bad?’: Active Learning, Productive Chaos, and Teaching New Religious Movements.” Teaching Theology and Religion 18 (2): 121-132. https://doi.org/10.1111/teth.12274.

Zurkowski, P. G. 1974. “The Information Service Environment Relationships and Priorities.” Related Paper No. 5. Washington, D.C.: National Program for Library and Information Services. https://eric.ed.gov/?id=ED100391.

\section{ABOUT THE AUTHORS}

Marianne Delaporte Kabir currently runs Sacred Beginnings Workshops, working with mothers around issues of spirituality. She is professor emeritus at Notre Dame de Namur University where she chaired the department of philosophy and religious studies. She holds a PhD from Princeton Theological Seminary and an MA from the Graduate Theological Union.

Sanjyot Pia Walawalkar currently works at Skyline College as Outreach and Equity Librarian. Prior to that she worked at Notre Dame de Namur University as Instructional Design Librarian. She holds an MLIS from Kent State University; an MA in German from Ohio State University; and an MA in English Literature from University of Mumbai. 